\title{
Living in a seasonal world: 15 th international hibernation symposium
}

\author{
Frank van Breukelen ${ }^{1} \cdot$ Jenifer Utz ${ }^{1}$
}

Received: 27 March 2017 / Accepted: 4 April 2017 / Published online: 10 April 2017

(C) Springer-Verlag Berlin Heidelberg 2017

This special issue of the Journal of Comparative Physiology B is dedicated to papers arising from the 15th International Hibernation Symposium held in Las Vegas, NV, USA from July 31-August 4th, 2016. These symposia occur every 4 years and bring together virtually all of the world's experts on mammalian hibernation. The 2016 program was primarily focused on mammalian hibernation with presentations on topics such as the evolution or plasticity of torpor use, how hibernation impacts on physiological systems such as the immune system, muscles, or bones, the molecular underpinnings of hibernation, and biomedical implications and prospects from hibernation. Mammals such as ground squirrels, bats, tenrecs, bears, echidnas, dormice, and lemurs were discussed. However, there was also discussion about birds, fish, lizards, and snakes and even gut microbial communities. Approaches towards solving problems spanned from ecological to physiological to biochemical and molecular strategies. Importantly, the program extended beyond hibernation and included the basic science of thermoregulation, hypoxia tolerance, brown adipose tissue function, and cold adaptation. Perhaps, most extraordinary about these meetings is the lack of formal rules or programming guidelines. The meeting was organized based on contributions and truly reflects the diversity of evolving research paradigms. Posters were encouraged to reflect the latest projects and allowed for insightful discussion.

Communicated by G. Heldmaier.

Frank van Breukelen

frank.vanbreukelen@unlv.edu

1 University of Nevada, Las Vegas, USA
A brief history of the 15 times the international hibernation community has come together is warranted. The first meeting was held May 13-15, 1959 at the Massachusetts Institute of Technology Endicott House (see Table 1). The 26 presented papers in that first meeting focused greatly on the physiology of hibernation and has set the tone for the ensuing meetings. One of the highlights of the meeting and subsequent symposium volume were the candid discussions (Lyman and Dawe 1960). Members of the hibernation community shared insight after each presentation and discussed the future directions of the field. Some of this discussion is seemingly humorous in retrospective. In a discussion as to the 'validity of the term, hibernation', one participant debated the meaning of 'validity'-perhaps highlighting the historical difficulty, the field has had with nomenclature that suitably describes the extraordinary diversity of torpor use. The community was trying to separate out hypothermia from hibernation-a problem that we grappled with even in the 2016 meeting. Indeed, many of the topics pursued in the first meeting are still relevant 58 years later. We know much more than we did then, but we still struggle with the basic questions as to why do animals hibernate or why do almost all hibernators experience periodic euthermic arousals during the winter.

Every 3-6 years, meetings were held. Proceedings were published a year or two after the meeting. The impact of these meetings was tremendous even early on. As far as we can tell, the first suggestion that brown adipose tissue was thermogenic came from Robert E. Smith in the 2nd symposium in 1962. Smith discussed how no satisfactory physiological role had yet been assigned to brown adipose tissue and then presented data that supported a role for thermogenesis and homeothermy. The ideas presented at the meeting in 1962 led to the landmark paper in Science demonstrating the role of brown adipose tissue in thermogenesis 
Table 1 Summary of international hibernation symposia

\begin{tabular}{llll}
\hline Symposium & Year & Location & Principle organizers \\
\hline 1 & 1959 & Dedham, Massachusetts, USA & C. P. Lyman and A. R. Dawe \\
2 & 1962 & Helsinki, Finland & P. Suomalainen \\
3 & 1965 & Toronto, Canada & K. C. Fisher, A. R. Dawe, C. P. Lyman, E. Shönbaum, and F. E. South \\
4 & 1971 & Aspen, Colorado, USA & F. E. South, J. P. Hannon, J. R. Willis, E. T. Pengelley, N. R. Alpert \\
5 & 1977 & Jasper, Canada & L. Wang and J. W. Hudson \\
6 & 1980 & Prague, Czechoslavakia & X. J. Musacchia and L. Jansky \\
7 & 1985 & Fallen Leaf Lake, California, USA & H. C. Heller, X. J. Musacchia and L. C. H. Wang \\
8 & 1989 & Le Hohwald, France & A. Malan and B. Canguilhem \\
9 & 1993 & Crested Butte, Colorado, USA & C. Carey, G. L. Florant, B. A. Wunder, and B. Horwitz \\
10 & 1996 & Cradle Mountain, Tasmania, Australia & F. Geiser, A. J. Hulbert, and S. C. Nicol \\
11 & 2000 & Jungholz, Austria & G. Heldmaier and M. Klingenspor \\
12 & 2004 & Sailing from Vancouver, Canada to & B. M. Barnes and H. V. Carey \\
13 & 2008 & Seward, Alaska, USA & \\
14 & 2012 & Semmering, Austria & B. G. Lovegrove and A. E. McKechnie \\
15 & 2016 & Las Vegas, Nevada, USA & T. Ruf, C. Bieber, W. Arnold, and E. Millesi \\
16 & 2020 & Gronigen, The Netherlands & F. van Breukelen and J. C. Utz \\
\hline
\end{tabular}

The first 14 symposia have associated edited volumes

(Smith and Hock 1963). By the fourth meeting, an appreciation of what might be learned using a comparative approach extending beyond mammalian hibernation was particularly evident. Topics and approaches diverged from physiological mechanism. Model organisms varied and eventually included invertebrates. Over time, the hibernation community settled into a schedule of one meeting every 4 years with an edited book produced for each meeting. In 2012, the community elected to no longer produces the edited book but instead contributes to this volume. Through its history, the meetings changed names in an attempt to better define the attending community that was constantly evolving. Regardless of what the meetings were called, the meetings maintained their role as the primary opportunity to bring the community together. The meetings became the venue wherein the field of the study of hibernation evolved. Different perspectives presented at the meetings helped shape ensuing research projects and questions. The result, evidenced in this volume, is that researchers are making significant strides in understanding the evolution, drive, and mechanisms of hibernation use.

\section{The grand challenges facing hibernation research}

Despite more and more hibernation biology having been elucidated, fundamental questions have persisted. Perhaps, one of the greatest assets to hibernation research and, arguably, one of its greatest liabilities have been the availability of many different models. A very large number of mammals hibernate and these hibernators represent most of the major clades. Early work focused on Boreal species using hibernation as an escape from the constraints of cold. Assumptions were made that were generalized to all hibernators. Even the early names for the meetings such as Life in The Cold reflect our biases of linking hibernation and the cold. However, important questions may be answered by availing ourselves of additional models. For instance, virtually, all hibernators experience periodic rewarming. More recent work demonstrates some tropical species that avoid use of periodic rewarming (tenrecs and dwarf lemurs in certain situations; reviewed in van Breukelen and Martin 2015). Inclusion of the Austral and tropical hibernators may provide a new mechanistic insight that will challenge our biases regarding the evolution of hibernation, the use of periodic rewarming, and even the role of abiotic factors such as fire in promoting torpor use. Some of the papers included here address such issues and we suspect an additional insight in the forthcoming years.

A large amount of mechanistic data now exist that address processes as varied as protein synthesis, kidney function, and ventilatory patterns during hibernation. Despite such advances, we still do not fully understand how an animal actually enters torpor. How is metabolism reduced? What are the contributions of active suppression of metabolic activities vs the consequences of passive depression from the reduced body temperature? We believe that the answers to these questions will come and hope that reconciliation of these data with an evolutionary perspective will finally addresses why some animals hibernate. 
Finally, we expect increased adoption of nature's strategies into biomedical application. Work within this issue has tremendous biomedical implication. How do we translate what a hibernator does into a therapeutic strategy that can extend lifespan, respond to an emergency situation like clinical hypothermia, and/or improve the quality of life for humans?

The study of mammalian hibernation has yielded many important and exciting findings. We suspect that many more findings are awaiting discovery and look forward to reading about them.

\section{References}

Lyman CP, Dawe AR (1960) Mammalian Hibernation. In: Proceeding of the first international hibernation symposium on natural mammalian hibernation. May 13-15, 1959. Bull Mus Comp Zool, 124. p 549

Smith RE, Hock RJ (1963) Brown fat: thermogenic effector of arousal in hibernators. Science 140:199-200

van Breukelen F, Martin SL (2015) The hibernation continuum: physiological and molecular aspects of metabolic plasticity in mammals. Physiol 30: 273-281 